\title{
WHITE BOX TESTING PADA SISTEM PEMESANAN DESAIN SABLON BERBASIS WEB
}

\author{
Abdi Pandu Kusuma ${ }^{1}$, Bayu Setiawan ${ }^{2}$ \\ ${ }^{1,2}$ Teknik Informatika, Fakultas Teknologi Informasi, Universitas Islam Balitar Blitar \\ Jl.Mojopahit 4A Blitar \\ Telepon. 085855851884 \\ E-mail: pans.uib1blitar@gmail.com,usebayu@gmail.com
}

\begin{abstract}
Ordering a screen printing design is built as a supporting tool to anticipate cheating buyers in ordering goods that are normally done through the marketplace. By using this system the user must enter the order number obtained after the customer makes an order in the marketplace for verification if they want to make a design order. Admin can manage user access to order designs and manage the design queue properly. White box testing method is done to find out how the system works structurally, besides to find out things that might happen when the system is run. In the white box test on the user login page and the design ordering page, the system works well as evidenced from the testing phase as in Cyclomatic Complexity and Matrix produces a value of 2 for the user login page and 1 for the design message page.
\end{abstract}

\section{Keyword: White Box, Screen Printing, Ordering}

\section{PENDAHULUAN}

Pada penelitian ini dilakukan pada perusahaan percetakan yang biasa mengerjakan aneka cetakan mulai dari cetakan manual dan juga cetakan digital.

Sistem yang dijalankan dalam perusahaan percetakan ini umumnya dilakukan saat pelanggan melakukan pemesanan sablon plastik melalui marketplace, Shopee atau Tokopedia, pelanggan harus menyiapkan konsep desainnya terlebih dahulu, dan dikirim menggunakan aplikasi WhatsApp ke kontak toko, selanjutnya toko akan membuatkan desain sablonnya dan dikirimkan kembali ke pelanggan. Jika toko mendapat banyak permintaan desain, maka terjadi penumpukan chat pada aplikasi dan sering terlupa antrian desain yang harus dikerjakan dahulu. Selain itu, juga ada beberapa konsep desain yang belum di kerjakan. Apabila hal ini terus menerus terjadi dapat berpengaruh terhadap penilaian pelanggan mengenai toko tersebut.

Permasalahan yang lain dalam perusahaan percetakan ini masih belum bisa memastikan bahwa pelanggan yang pesan desain itu sudah melakukan pesanan ke marketplace. Hal ini menyebabkan timbulnya kecurangan pelanggan. Contohnya pesan desain terlebih dahulu, setelah desain selesai tidak jadi melakukan pesanan produk yang bersangkutan. Hal ini dapat merugikan toko dikarenakan membuang waktu yang percuma untuk pembuatan desain pelanggan yang batal melakukan pesanan.

Saat sebuah sistem di jalankan ada banyak kemungkinan yang bisa terjadi, entah itu berjalan dengan lancar, ataupun terdapat suatu masalah atau kendala, oleh karena itu saat pembuatan sistem perlu dilakukan pengujian secara keseluruhan baik dari sisi fungsional (black box) maupun structural (white box) untuk mengetahui sistem tersebut berjalan sesuai fungsinya (Abdul, 2012), selain itu dapat mengetahui hal-hal yang mungkin akan terjadi saat sistem tersebut di jalankan dan untuk mengetahui cara kerja sistem tersebut.

\section{METODE}

a. Flowchart Sistem

Sistem dalam penelitian ini terdapat beberapa halaman yang setiap halamannya mempunyai isi atau fungsi yang berbeda seperti halaman home, halaman pesan desain, dan halaman login. Halaman login hanya digunakan untuk admin. Perancangan sistem pemesanan desain sablon berbasis website ini dapat ditampilkan seperti gambar 1 .

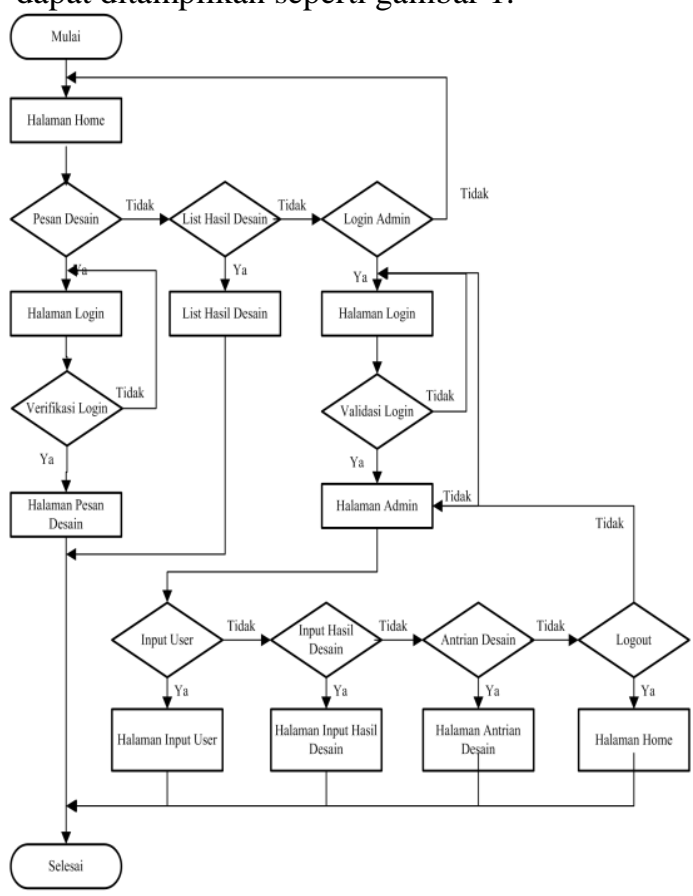

Gambar 1. Flowchart Sistem 
b. DFD (Data Flow Diagram)

1) DFD Level 0.

Pada gambar 2 ditampilkan proses-proses dan aliran data pada sistem secara keseluruhan.

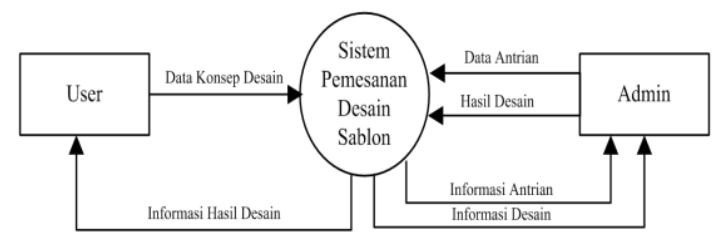

Gambar 2. DFD Level 0

Gambar 1 menunjukan bahwa semua aliran data yang ada menuju pada satu proses, yaitu proses Sistem Pemesanan Desain Sablon Ada dua entitas yang terlibat di sistem ini yaitu entitas Admin dan entitas User. Masing-masing entitas memiliki data masukkan dan data keluaran pada sistem.

2) DFD Level 1.

Pada gambar 3 ditunjukkan alur yang lebih spesifik tentang sistem, dimana termasuk hasil pemecahan dari DFD level 0.

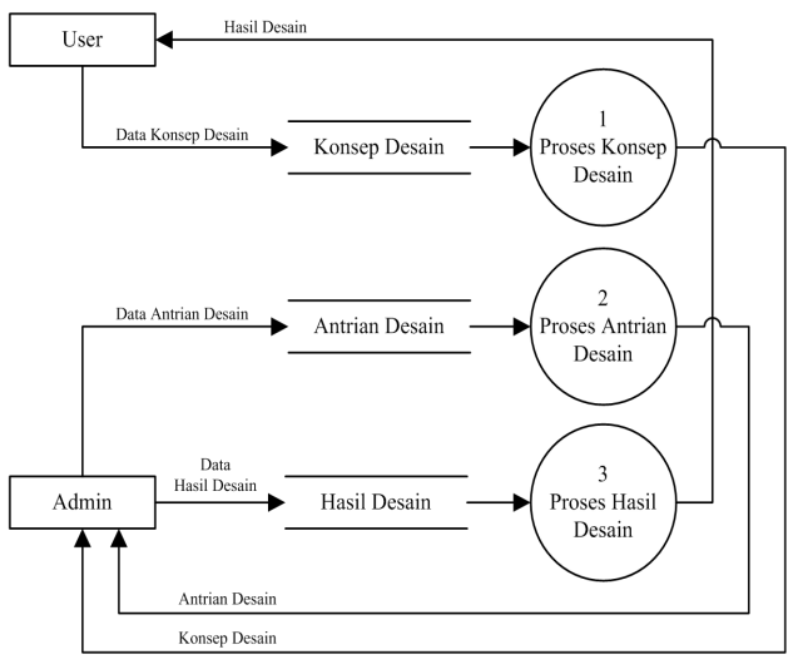

Gambar 3. DFD Level 1

Pada gambar 3 memiliki tiga proses yaitu proses konsep desain, proses antrian desain, dan proses hasil desain dimana setiap proses memiliki aliran data input maupun output dari atau ke data store.

3) ERD (Entity Relationship Diagram).

Pada gambar 4 ditunjukan struktur data dan hubungan antar data pada sistem pemesanan desain sablon.

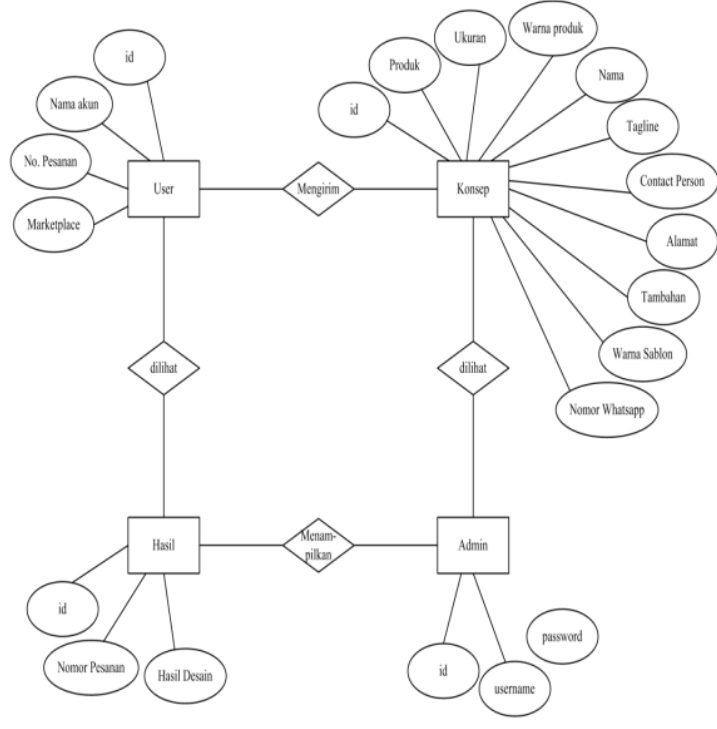

\section{Gambar 4. Entity Relationship Diagram pada sistem}

\section{PEMBAHASAN}

\subsection{Tampilan Sistem}

Pada gambar 5 ditunjukkan tampilan halaman pemesanan desain sablon.

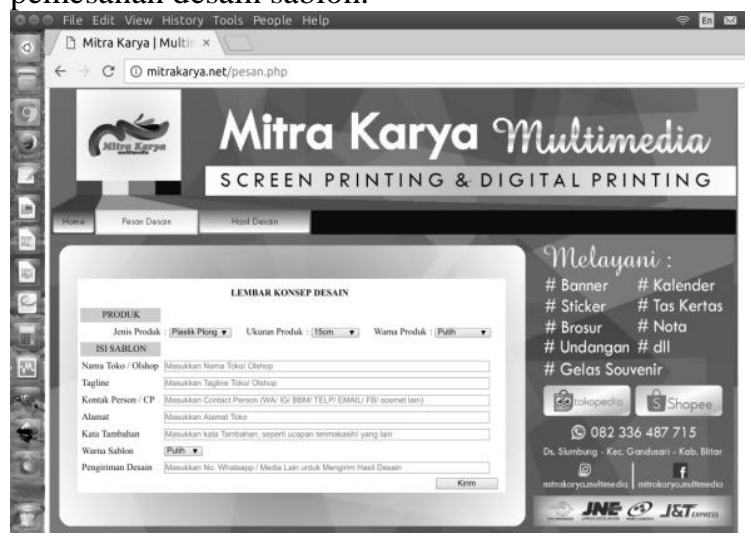

Gambar 5. Halaman Pesan Desain

Dalam sistem pemesanan desain sablon ini terdapat halaman pesan desain dimana halaman yang akan tampil ketika user telah berhasil login halaman ini digunakan dalam melakukan pesanan desain.

\subsection{Pengujian Whitebox}

Pada pengujian whitebox terdapat 2 halaman yang dilakukan pengujian, yaitu halaman login user dan halaman pesan desain.

\section{a. Pengujian pada halaman login user.}

Dalam pengujian di halaman login user terdapat beberapa tahapan berikut :

1) Pemetaan Source Code halaman login user

Pada tahap yang ini dipetakan bagian-bagian dari source code actloginuser.php ke dalam tabel 1 berikut. 
Tabel 1. Struktur Actloginuser.php

\begin{tabular}{|c|c|}
\hline Path & Source Code \\
\hline 1 & $<$ ?php \\
\hline 2 & $\begin{array}{l}\text { include "database.php"; } \\
\quad \text { \$akun } \\
\text { \$_POST['akun']; } \\
\quad \text { \$nopesan = } \\
\text { \$_POST['nopesan']; } \\
\text { \$marketplace= } \\
\text { \$_POST['marketplace']; }\end{array}$ \\
\hline 3 & $\begin{array}{l}\quad \text { \$login }= \\
\text { mysqli_query (\$connect, "SELECT * } \\
\text { FROM user WHERE } \\
\text { nopesan='\$nopesan' AND } \\
\text { marketplace = '\$marketplace' "); } \\
\text { \$row=mysqli_fetch_array (\$login); }\end{array}$ \\
\hline 4 & 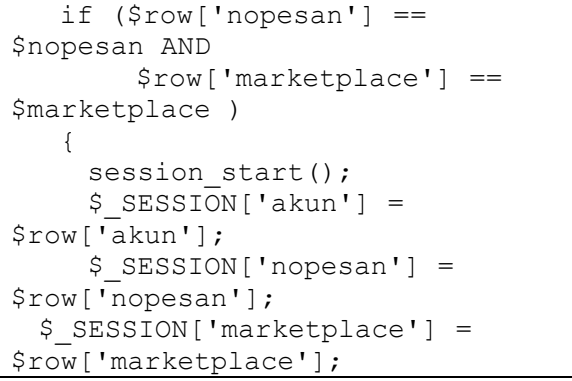 \\
\hline 5 & header ('location:pesan.php') ; \\
\hline 6 & 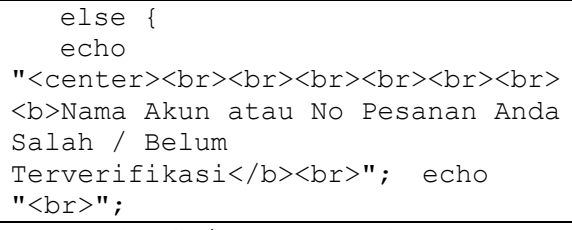 \\
\hline 7 & $\begin{array}{l}\text { echo "<input type=button } \\
\text { value='Ulangi Login' } \\
\text { onclick=location.href='loginuser. } \\
\text { php'></center }>\text { "; }\end{array}$ \\
\hline 8 & ?> \\
\hline
\end{tabular}

2) Membuat flowgraph dari pemetaan source code.

Pada gambar 6 ditunjukkan tampilan flowgraph dari struktur actionloginuser.php.

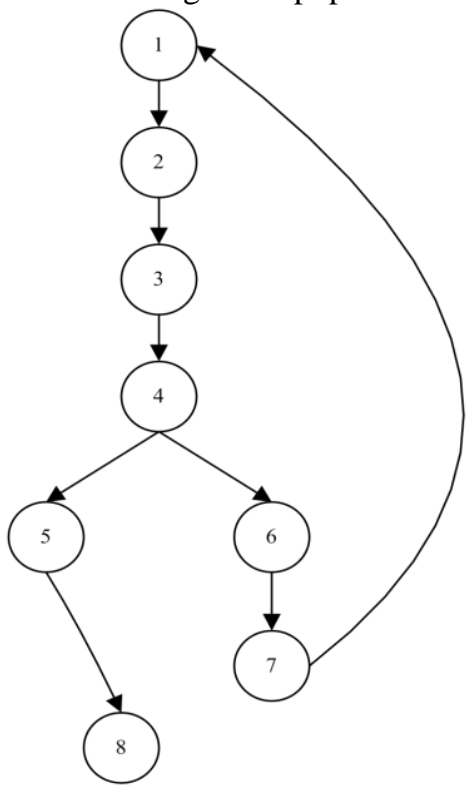

Gambar 6. Flowgraph actionloginuser.php
Pada gambar 6 terdapat 1 percabangan pada nomor 4, yaitu nomor 5 yang artinya verifikasi pada nama akun, no, pesanan itu valid dan proses sistem selesai. Sedangkan pada nomor 6 yang berarti sistem gagal memverifikasi nama akun, nomor pesanan user, sistem akan menampilkan pesan gagal login, berlanjut pada proses nomor 7 yaitu meminta user untuk login kembali, dan sistem kembali berulang ke awal.

\section{3) Cyclomatic Complexity.}

Pada gambar 6 terdapat beberapa nodes, edges, dan predicated nodes untuk menghitung Cyclomatic Complexity berikut.

$$
\text { a) } \begin{aligned}
\mathrm{V}(\mathrm{G}) & =\mathrm{E}-\mathrm{N}+2 \\
\mathrm{~V}(\mathrm{G}) & =8-8+2 \\
= & 2 \\
\text { b) } \mathrm{V}(\mathrm{G}) & =\mathrm{P}+1 \\
\mathrm{~V}(\mathrm{G}) & =1+1 \\
= & 2
\end{aligned}
$$

Keterangan :

$\mathrm{E}=$ jumlah edges pada flowgraph

$\mathrm{N}=$ jumlah nodes pada flowgraph

$\mathrm{P}=$ jumlah predicates nodes pada flowgraph

\section{4) Independent Path.}

Dari hasil penghitungan Cyclomatic Complexity terpadat 2 path berikut.

Path $1: 1-2-3-4-5-8$

Path $2: 1-2-3-4-6-7-1-2-3-4-5-8$

\begin{tabular}{|c|c|c|c|c|c|c|c|}
\hline & 12 & 34 & 5 & 6 & 7 & 8 & $n(E)-1$ \\
\hline 1 & 1 & & & & & & $1-1=0$ \\
\hline 2 & & 1 & & & & & $1-1=0$ \\
\hline 3 & & 1 & & & & & $1-1=0$ \\
\hline 4 & & & 1 & 1 & & & $2-1=1$ \\
\hline 5 & & & & & & 1 & $1-1=0$ \\
\hline 6 & & & & & 1 & & $1-1=0$ \\
\hline 7 & 1 & & & & & & $1-1=0$ \\
\hline 8 & & & & & & & $0-0=0$ \\
\hline & Jumla & $a+1$ & & & & & $1+1=2$ \\
\hline
\end{tabular}

\section{5) Graph Matriks.}

Berdasarkan 2 path yang telah ditentukan di dalam Independent Path dapat di uji dengan graph matrix pada tabel 2 berikut.

Tabel 2. Graph Matriks 


\section{6) Skenario Uji.}

Pada tahap ini dilakukan ujicoba pada halaman login user dengan memasukkan akun, no. pesanan dan marketplace sesuai dengan skenario uji yang telah di tetapkan pada bab sebelumnya sebagai berikut :

a) Langkah pertama dengan memasukkan nama akun"nurmala", no pesanan“95596886", dan marketplace "tokopedia" maka muncul suatu pesan Login Gagal dan diminta untuk login ulang. Seperti ditampilkan pada gambar 7 berikut.

Nama Akun atau No Pesanan Anda Salah / Belum Terverifikasi

Ulangi Login

\section{Gambar 7. Login gagal}

b) Langkah kedua dengan memasukkan nama akun "adelasuryapertiwi",no pesanan "17100623 004DDG3", dan marketplace "Shopee" maka tampil halaman pesan desain, itu diartikan sebagai login sukses. Seperti pada gambar 8 berikut.

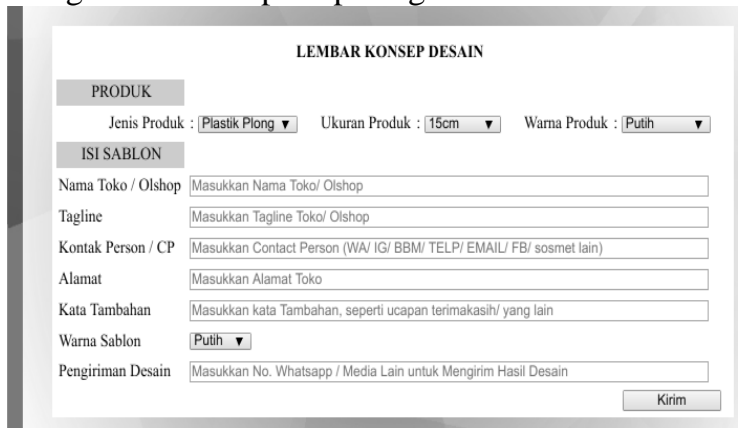

Gambar 8. Login Berhasil

Dari Skenario Uji di atas dapat disimpulkan bahwa saat melakukan beberapa tes dengan memasukkan nama akun "nurmala", no pesanan "95596886", dan marketplace "tokopedia" maka muncul suatu pesan Login Gagal dan diminta untuk login ulang. Sedangkan bila memasukkan nama akun "adelasuryapertiwi", no pesanan "17100623004DDG3", dan marketplace "Shopee", maka proses kemunculan pesan Login Gagal akan dilewati dan masuk ke halaman pesan desain. Dari penjelasan ini dapat digambarkan ke dalam tabel berikut.

\section{Tabel 4. Hasil Skenario Uji}

\begin{tabular}{|c|c|c|c|c|}
\hline No. & $\begin{array}{l}\text { Nama } \\
\text { Akun }\end{array}$ & $\begin{array}{c}\text { No } \\
\text { Pesanan }\end{array}$ & $\begin{array}{c}\text { Mark } \\
\text { etpla } \\
\text { ce }\end{array}$ & Hasil \\
\hline 1 & nurmala & $\begin{array}{c}955968 \\
86\end{array}$ & $\begin{array}{l}\text { Toko } \\
\text { pedia }\end{array}$ & $\begin{array}{c}\text { Gagal - } \\
\text { Muncul } \\
\text { Pesan } \\
\text { Gagal }\end{array}$ \\
\hline 2 & $\begin{array}{c}\text { adelasury } \\
\text { apertiwi }\end{array}$ & $\begin{array}{l}171006 \\
23004 \mathrm{D}\end{array}$ & $\begin{array}{l}\text { Shop } \\
\text { ee }\end{array}$ & $\begin{array}{c}\text { Berhasil } \\
\text { - Masuk } \\
\text { Halaman }\end{array}$ \\
\hline
\end{tabular}

DG3

Pesam

Desain

\section{b. Pengujian pada Halaman Desain Pesan}

Pada pengujian di halaman pesan desain terdapat beberapa tahapan berikut.

1) Pemetaan Source Code halaman pesan desain.

Pada tahap yang pertama peneliti memetakan bagian -bagian dari source code actpesan.php ke dalam tabel berikut.

\section{Tabel 4. Struktur Actloginuser.php}

\begin{tabular}{|c|c|}
\hline Path & Source Code \\
\hline 1 & $<? \mathrm{php}$ \\
\hline 2 & 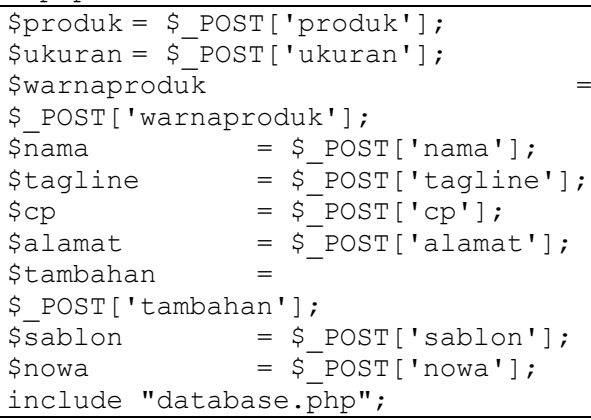 \\
\hline 3 & $\begin{array}{l}\text { \$kirim }=\text { mysqli_query (\$connect, } \\
\text { "INSERT INTO konsep VALUES (NULL, } \\
\text { '\$produk', '\$ukuran', } \\
\text { '\$warnaproduk', '\$nama', } \\
\text { '\$tagline', '\$cp', '\$alamat', } \\
\text { '\$tambahan', '\$sablon', '\$nowa') ") } \\
\text { or die(mysqli error()); }\end{array}$ \\
\hline 4 & $\begin{array}{l}\text { echo "Data Berhasil Di Kirim <meta } \\
\text { http-equiv=refresh } \\
\text { content=3; url=hasildesain.php >"; }\end{array}$ \\
\hline 5 & ?> \\
\hline
\end{tabular}

2) Membuat Flow graph dari pemetaan source code.

Pada gambar 9 dipetakan bagian - bagian dari source code actpesan.php ke dalam tabel. Peneliti membuat gambaran alur sistem atau flow graph berikut.

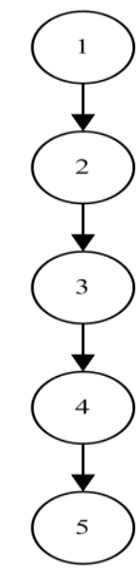

\section{Gambar 9 Flow Graph actpesan.php}

Gambar 9 tidak ada percabangan pada proses yang ada dihalaman pesan desain. 


\section{3) Cyclomatic Complexity.}

Pada gambar 9 terdapat beberapa nodes, edges, dan predicated nodes untuk menghitung Cyclomatic Complexity berikut.

a) $\mathrm{V}(\mathrm{G})=\mathrm{E}-\mathrm{N}+2$

$\mathrm{V}(\mathrm{G})=4-5+2$

$=1$

b) $\quad \mathrm{V}(\mathrm{G})=\mathrm{P}+1$

$\mathrm{V}(\mathrm{G})=0+1$

$=1$

Keterangan :

$\mathrm{E}=$ jumlah edges pada flowgraph

$\mathrm{N}=$ jumlah nodes pada flowgraph

$\mathrm{P}=$ jumlah predicates nodes pada flowgraph

\section{4) Independent Path..}

Dari hasil penghitungan Cyclomatic Complexity terpadat 1 path berikut.

Path $1: 1-2-3-4-5$

\section{5) Graph Matriks.}

Berdasarkan 2 path yang telah ditentukan di dalam Independent Path dapat di uji dengan graph matrix pada tabel 2 berikut.

Tabel 5. Graph Matriks

\begin{tabular}{c|ccccccccc}
\hline & 1 & 2 & 3 & 4 & 5 & 6 & 7 & 8 & $\mathrm{n}(\mathrm{E})-1$ \\
\hline 1 & & 1 & & & & & & \\
2 & & & & & & & & & $1-1=0$ \\
3 & & & & & & & & & $1-1=0$ \\
3 & & & & 1 & & & & $1-1=0$ \\
4 & & & & & 1 & & & $1-1=0$ \\
\hline & & & & & & & \\
\hline & & & & & Jumlah +1 & $0+1$ & $=1$
\end{tabular}

\section{6) Skenario Uji}

Pada pengujian halaman desain pesan dapat diketahui bahwa halaman tersebut tidak ada percabangan yang berarti tidak ada perulangan pada aplikasi tersebut.

Pada tahap Cyclomatic Complexity dan Matrix graph, menghasilkan nilai yang sama yaitu 1.maka pengujian pada halaman pesan desain berjalan dengan baik.

\section{KESIMPULAN}

Pada pengujian white box pada halaman login user dan halaman pemesanan desain terdapat beberapa tahapan seperti Pemetaan Source Code, Membuat Flow graph, Penghitungan Cyclomatic Complexity, Menentukan Independent Path, Pembuatan Graph Matrix dan Melakukan Skenario Uji pada halaman login user.
Dalam tahap pengujian di halaman login user, dan pesan desain menggunakan Cyclomatic Complexity dan Matrix graph, dihasilkan nilai yang sama yaitu 2 untuk halaman login user dan 1 untuk halaman pesan desain. Maka dapat disimpulkan bahwa pengujian white box berjalan dengan baik karena pada setiap tahap pengujian menghasilkan nilai yang sama

\section{PUSTAKA}

Dian N. 2015. Pengertian Desain Secara Umum \& Khusus (Online). (http:// pengertiandesain umumdankhusus. blogspot.co.id, diakses 18 Agustus 2018).

Mulyanto Agus. 2009. Sistem Informasi Konsep dan Aplikasi, Yogyakarta : Pustaka Pelajar.

Prakoso, Syaifullah. A. 2014. Aplikasi Penanganan Transaksi Order Pada PT. Allib Indonesia. STIKOM Institutional Repositories (Online). (http://sir.stikom.edu/id/eprint/1285, diakses 14 September 2018).

Rouf Abdul. 2012. Pengujian perangkat lunak dengan menggunakan metode White box dan black box. Jurnal Online STMIK HIMSYA

Santoso O. A. 2016. Pengertian Website dan Contohnya (Online). (https://oliviaagnez. wordpress.com/2016/02/18/pengertian-websitedan-contohnya, diakses 10 September 2018). 